\title{
Hydro-climatology Characterization of Degraded Lwamunda Forest Catchment Based on Probability Distributions
}

\author{
Ausi Abubakar Ssentongo ", Nsubuga Francis Waswa, Daniel Darkey \\ Department of Geography, Geo-informatics and Meteorology, Faculty of Natural and Agricultural Sciences, University of Pretoria, Pretoria, \\ South Africa \\ Email address: \\ ausisento@gmail.com(A. A. Ssentongo), Francis.Nsubuga@up.ac.za(N. F. Wasswa), Daniel.darkey@up.ac.za (D. Darkey) \\ ${ }^{*}$ Corresponding author
}

\section{To cite this article:}

Ausi Abubaker Ssentongo, Nsubuga Francis Waswa, Daniel Darkey. Hydro-climatology Characterization of Degraded Lwamunda Forest Catchment Based on Probability Distributions. Earth Sciences. Vol. 9, No. 2, 2020, pp. 65-75. doi: 10.11648/j.earth.20200902.13

Received: November 21, 2019; Accepted: January 27, 2020; Published: March 17, 2020

\begin{abstract}
Hydroclimatology assessment is conventionally based on area data for identification of change patterns and trends. In this paper, monthly averages, maximum seasonal and maximum annual hydro- climatology data series from Lwamunda forest catchment area in central Uganda have been analyzed in order to determine the appropriate probability distribution models for the underlying climatology (i.e. rainfall, soil moisture content, evapotranspiration and temperature). A total of 7 probability distributions were considered and three goodnessof- fit tests were used to evaluate the best-fit probability distribution model for each hydro-climatology data series. They were Lilliefors (D), Anderson-Darling (AD), and Cramer-Von Mises (W2). A ranking metric based on the test statistic from the three GoF tests was used to select the most appropriate probability distribution model capable of reproducing the statistics of the hydroclimatological data series. The best fit probability distribution was selected based on the minimum sum of the three test statistic. Results showed that different best fit probability distribution models were identified for the different data series depending on location and on temporal scales which corroborate with those reported in literature. With the exception of soil moisture content for annual and seasonal maximum series who have the same best fit model. The same applied to evapotranspiration seasonal maximum and near surface temperature seasonal maximum as well as monthly near surface temperatures have the same best fit model. The soil moisture content data series was best fit by the Weibull probability distribution, rainfall series was best fit by Chi square and Gamma probability distributions. The evapotranspiration data series was best fit by Logistic and Extreme value maximum (Gumbel) probability distributions. Finally for near surface temperature it was best fitted by Logistic and Gumbel probability distributions. The contribution of this study lies in the use of hydroclimatological data series including soil moisture content from the area that had forest cover change to analyzeits impact on water resources patterns. The contribution is important for agricultural planning and forest managers' simulation of forest degradation impacts.
\end{abstract}

Keywords: Hydroclimatilogy, Probability Distributions, Climate Variability, Water Resources

\section{Introduction}

The interaction between hydrological and climatological factors in tropical areas among others, determines the magnitude and quality of water resources available for both humans and other living creatures. In particular forests and water bodies are crucial in influencing the hydrological circle within the tropics. Management of these resources that are increasingly becoming scarce is a key factor for their sustainable use. However, with increasing pressure from population growth and climate change and its variability, management of these resources becomes a challenge. Any change in their use indirectly constrains their availability on temporal and spatial scales. Climate variability and land cover change like forest cover change are consistently associated with changes in water balance accompanied with changes in other hydrological systems, such as the changing patterns of rainfall, drainage density and spring flow 
reduction, increasing evapotranspiration, changes in soil moisture and surface run off. With changes in hydrological cycle and systems, subsequently impact on the quantity and quality of regional water resources on land.

Advances in the interactions of land surface-atmospheric components have shown an increasing interest in how human induced land use/cover changes influence climatic variables such as rainfall [1, 2], temperature and evapotranspiration. Identifying and understanding such interactions' consequences is however complicated by the difficulties of delineating causing factors from compounding factors [38]. Since there is difficulty with determining cause and effect in a complex interacting systems with disparate characteristic time scale in a robust way. One of such interactions is how land cover changes influence soil moisture content and in turn how soil moisture content impact on overlying boundary layer evolution which carries with it longer time-scale variability in the region [1]. With land cover change, investigations of the interaction between land cover and atmosphere on statistical measures of climate states need to focus both on immediate interactions and the feedbacks that operate at longer time scales. In this current work interactions considered are based on local experience of the change in forest cover into various land uses and how subsequently sparks changes in soil water content, stream outflow, evapotranspiration, rainfall and temperature. Thus it's important to understand the feedbacks and interactions between land cover changes and its impact on water resources patterns and dynamics.

Many regions on the African continent have suffered from climate change and variability for decades. Where semiarid regions of the Northern Hemisphere have exhibited interannual and inter seasonal rainfall fluctuations, indicative of land atmospheric feedback mechanism [3, 37]. The African continent is expected to become warmer in this century larger than the global trends. Seasonal variability of climatic parameters could adversely affect amount of rainfall, water resources and output from agriculture [4, 5]. There is expected increase in climate variability in the coming decades as rainfall is projected to reduce and temperatures to increase. Therefore, it's crucial for purposes of planning and management of water resources to properly assess and improve understanding of how past changes in climate events affect people's livelihood and access to water.

According to Mubiru [6], human activities like deforestation that trigger land use and land cover changes do influence climate and other drivers of land use change, at varying levels. Rainfall patterns in most parts of African continent exhibit high degree of inter-annual and intra-seasonal variability over spatial and temporal scales [41]. The amount and pattern of rainfall are considered to be key drivers to water resources changes and fluctuation in agricultural productivity. According to Lazaro [7], long term records of rainfall usually provide information about rainfall patterns of variability and rainfall patterns are often inferred from computation of probability distribution functions such that normal distribution function is mostly used in rainfall analysis. Although commonly used in rainfall analysis, there are other instances where rainfall distributions were found to be neither normal norsymmetrical [36], Jackson [8], annual rainfall was found to be skewed in semiarid areas and not in tropics. In Uganda rainfall is analyzed according to four seasons over most parts of the country, the seasons are DJF, MAM, JJA and SON $[9,10,41]$. These seasons contribute a mean annual rainfall approximately $1,200 \mathrm{~mm}$ [11], whileNEMA [12] estimates varying rainfall between $500 \mathrm{~mm}$ and $2800 \mathrm{~mm}$, averaging more

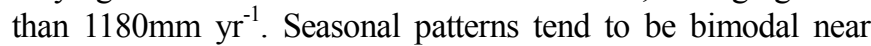
equator and uni-modal systems as we move away from equator $[13,14]$. However, most of rainfall studies do not tell us much about the magnitude of change and their distribution with confidence [15].

Studies on temperature trends predict variability and increase $[16,17]$. Climate trends studies in the country indicates that the period between 1975 and 2009, temperature increased by more than $0.8 \% \mathrm{yr}^{-1}$ while rainfall reduced by $8 \%$ between 1900 and 2009. Near surface temperature increased around $21^{\circ} \mathrm{C}$ in general and monthly minimum temperature will range $15^{\circ} \mathrm{C}$ (July) to $30^{\circ} \mathrm{C}$ in (Feb). Uganda experienced positive trends in both minimum and maximum temperatures over the period 1960-2008 [11] and usually the increase in near surface temperature have impact on ground water systems [18]. Projected increase in temperature by $2^{\circ} \mathrm{C}-2.5^{\circ} \mathrm{C}$ in about $50-80$ years to come [10], will have disastrous effects on agriculture production on which many rural people depend [19], on fish stocks and fish based livelihoods [20]. Higher temperatures are also expected to have effects on per capita productivity in warmer countries like Uganda although such predictability is not conclusive if temperature distribution pattern is not known. In general the projected changes in near surface temperature and rainfall implies that the country will experience observable hydroclimatological regime shifts in rainfall and temperature $[6$, $21,16,10]$, where the biggest impact will be on water resources.

Forest cover loss during the $20^{\text {th }}$ century was confirmed to increase evapotranspiration and decrease water yield significantly $[22,42]$. It's also important to note that forests regulate water storage beneath it and increases travel time for water to reach streams [22], this implies that forest cover loss would do the reverse which can only be accepted or refuted by empirical findings. The interaction feedbacks do hypothesize soil moisture content -rainfall feedback previously identified in other studies [39] as having a significant role in affecting the partitioning of water and energy balance at the surface through influence on evapotranspiration efficiency, albedo and thermal inertia [1]. This needs to be understood further under conditions of land cover change. Soil moisture content has a more local effect on climate through seasonal mean evapotranspiration and temperature. Such feedbacks will be better understood if there is more information on their distributions in a given area. In addition forest cover loss disrupts the hydrological cycle of a drainage basin by changing the balance between rainfall, evaporation and soil moisture content dynamics [23].

Studies on climate change in Uganda have focused on temperature and rainfall variability and few in other areas incorporating potential evaporation. Little is known about 
evapotranspiration inclusion in climate studies in the region and its probable distribution. In addition soil moisture content as a component used in drought monitoring and analysis has not been incorporated much in hydrometeorology and hydro-climatological studies in the region. In the East African region over the last 50 years, drought had been frequent and steadily increased [24]. It impacts on agricultural production, infrastructure, health, and household welfare through impacts on crop and livestock prices [25] is not much documented in empirical work. Uganda is projected to be water stressed by 2025 [10], this implies that for effective adaptation to climate variability, probability distributions of rainfall, evapotranspiration and soil moisture content are crucial as input decision tools in proper management of water resources.

While there are advances in modeling land-surface processes and atmospheric interactions under controlled conditions using catchment data, it can also be studied through direct analysis of model equations using observational data derived from satellite sensors and also fitting distributions. Therefore, assessing the nature of probability distribution models capable of reproducing statistical moments of hydro-climatological observations that could contribute towards generating long term series of rainfall, evapotranspiration and soil moisture content that is important for modeling water resource is crucial. The main objective of this study is to characterize hydroclimatological data series hypothesized on land surface-atmospheric feedback over a small area in rural Uganda by use of probability distribution functions. Thus studying land surface processes and atmospheric interactions through direct analysis of model equations and fitting probability distributions based on observational data derived from satellite sensors is a valuable contribution to the extant body of knowledge in earth interactions.

\section{Study Area}

The area is characterized by a dense network of water streams which draw water from forest catchment in the region and replenished by rainfall. Thus the area has no water body with tributary streams. The population distribution in the five subcounties is less than 50,000, with agriculture as the main industry, albeit with spatially significant urbanization and ever changing land use patterns. The documented climate parameters with the highest space-time variation over the region are rainfall and temperature which determines the spatial patterns of natural resources and land use activities. The study region includes two districts with particular focus on five sub-counties that fall under the zone 4 of agro-ecological zoning by the National Biomass Study of (2003). It's a zone of moist lowland and medium altitude areas covering most of Southern and Western Uganda in the Districts of Mpigi, Butambala, Masaka, Kabarole, Hoima, Kabale, Kisoro, Nebbi and Mbale (NBS, 2003). It lies between $32^{\circ} 10^{\prime} 0^{\prime \prime} \mathrm{E} \& 32^{\circ} 25^{\prime} 0^{\prime \prime} \mathrm{E}$, and $0^{\circ} 8^{\prime} 0^{\prime \prime} \mathrm{N} \& 0^{\circ} 24^{\prime} 0^{\prime \prime} \mathrm{N}$. Rainfall ranges from $750 \mathrm{~mm}$ to $2000 \mathrm{~mm}$, with a bimodal pattern of March-May (MAM) and September-November (SON). The minimum temperatures rangebetween $15-17.5^{\circ} \mathrm{C}$ minimum and maximum $17.5-20^{\circ} \mathrm{C}$ (Figure 1 below). The study area consists of all the 13 land cover classes (NBS, 1995) out of them five stratification make up the forest sector in Uganda. Land cover change in this area is uni-directional from forest to farm land, grassland, light vegetation and bare soil [26]. The unidirectional land cover change with no major lake in the study area implied having significant impacts on water resources in the region.

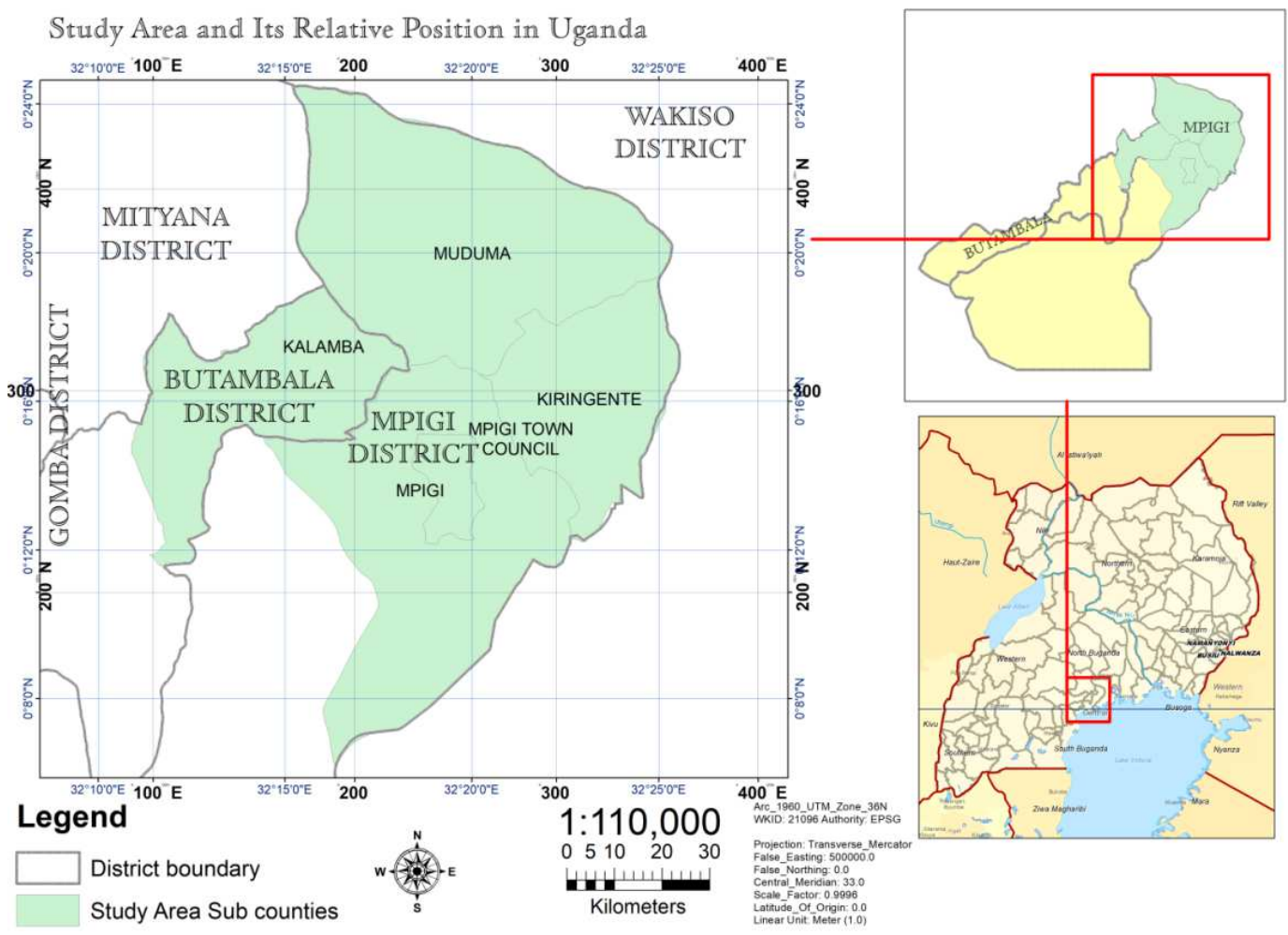

Figure 1. Location of the study area in Uganda. 
Its biomass range $80-180$ tones/ha of area covered with green during the period before 1990, with many forests both privately and publicly owned (central reserve forests). However, with the ever increasing population most of the green area has reduced, and many forests have been degraded and cleared to a level of 30-80 tones/ha in 2003 and since then decline in forest cover continued. Basalirwa's [27] classification of major systems that control the space-time characteristics of rainfall in Uganda includes among others the complex topographic features that are comprised of forests. These features introduce significant modifications over the region coupled with convection processes that generate a climatic pattern which is complex and changes rapidly over short distances [3].

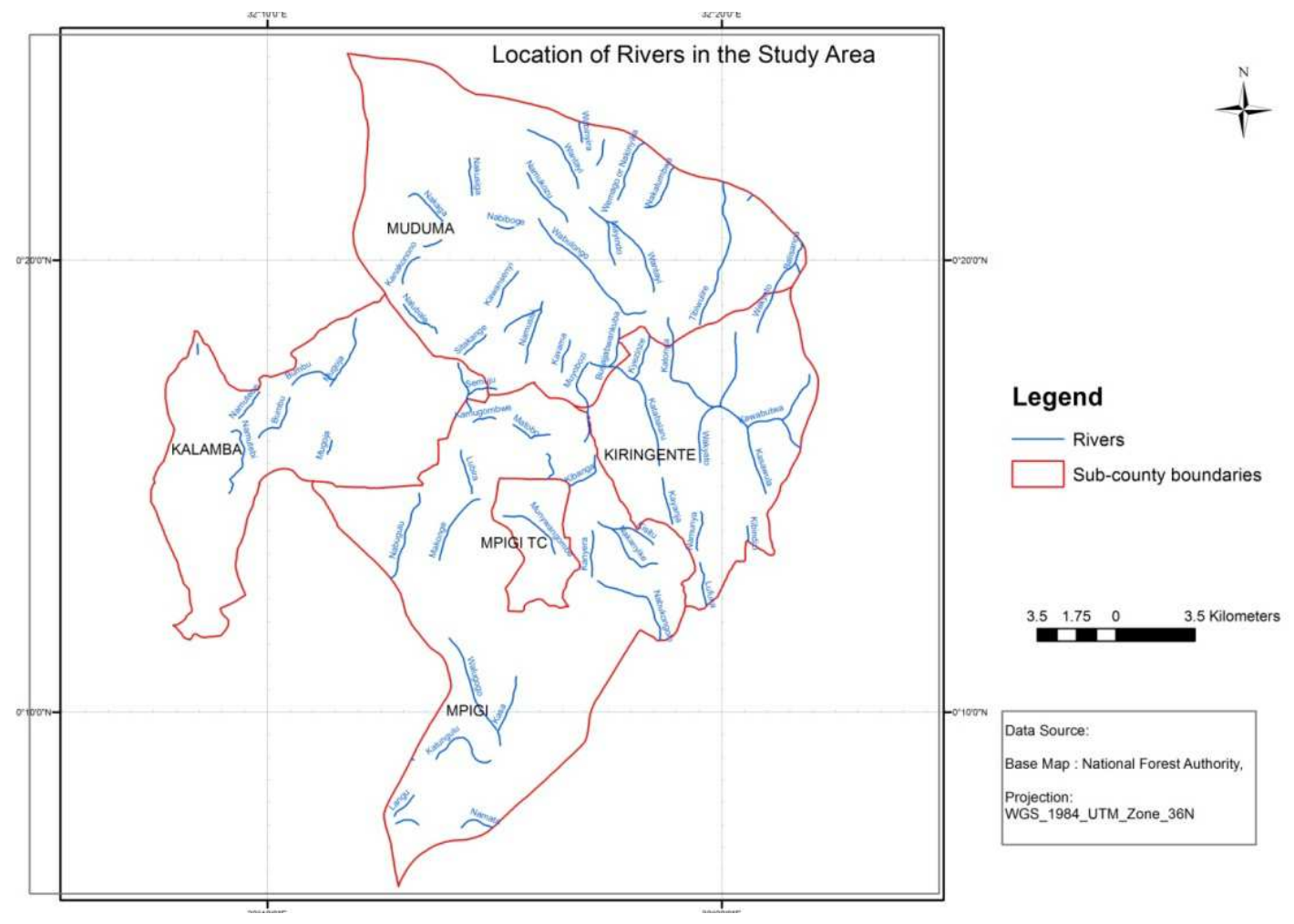

Figure 2. Location of rivers in the study area.

\section{Area Data}

Observational data of monthly averages, seasonal and annual time series for rainfall, soil moisture content, evapotranspiration and temperature were used. Monthly observed data of the selected variables with continuous time series from 1980 to 2010 were used for this study. The average record length is 31 years covering the early years when forest cover started to decline and the later years when management of forests had started to improve. The goal is to find whether the trend at the start could mirror the trend at the end of series. In this paper extreme hydro-climatological data series were considered. The annual mean maximum rainfall, soil moisture content, evapo-transpiration and temperatures were derived from the monthly data series for the period 1980 to 2010 (see table 1 below). Then seasonal mean maximum for the selected variables were derived. The data set was obtained from global land data assimilation system (GLDAS) under NOAH_M 2.0 as well as from CLSM025_V.2 and MERRA-2 Model. Data set of $1^{\circ}$ was used for rainfall, evapo-transpiration and temperature 0.5 . For soil moisture content the depth considered ranged between $10 \mathrm{~cm}$ to $100 \mathrm{~cm}$.
Table 1. Characteristics of the study variables.

\begin{tabular}{|c|c|c|c|}
\hline Data set & $\begin{array}{l}\text { Actual time } \\
\text { series }\end{array}$ & $\begin{array}{l}\text { Transformed } \\
\text { time series }\end{array}$ & $\begin{array}{l}\text { Period of } \\
\text { series }\end{array}$ \\
\hline Rainfall & $\begin{array}{l}\text { Monthly } \\
\text { averages }\end{array}$ & $\begin{array}{l}\text { Seasonal maxima } \\
\text { Annual maxima }\end{array}$ & $1980-2010$ \\
\hline Soil moisture & $\begin{array}{l}\text { Monthly } \\
\text { averages }\end{array}$ & $\begin{array}{l}\text { Seasonal maxima } \\
\text { Annual maxima }\end{array}$ & $1980-2010$ \\
\hline Evapotranspiration & $\begin{array}{l}\text { Monthly } \\
\text { averages }\end{array}$ & $\begin{array}{l}\text { Seasonal maxima } \\
\text { Annual maxima }\end{array}$ & $1980-2010$ \\
\hline Temperature & $\begin{array}{l}\text { Monthly } \\
\text { averages }\end{array}$ & $\begin{array}{l}\text { Seasonal maxima } \\
\text { Annual maxima }\end{array}$ & $1980-2010$ \\
\hline
\end{tabular}

\section{Methodology and Data Analysis}

The probability distributions presented in table 2 below were evaluated for the best-fit probability distribution model suitable for hydro-climatology dataset for the study region. Data analysis followed a step wise procedure. First, was for estimating the basic statistical descriptors for the data set for each time series used in the study. Secondly, was the description of the probability distribution functions used in their theoretical form. Explored each series by using a histogram with a density estimate, this was meant to provide 
insights on skewness, behavior in the tail, presence of multimodal behavior and data outliers. For each hydroclimatology series different probability distributions were fitted and the maximum likelihood estimator was used to estimate the corresponding parameters. Thirdly, this step involved testing the goodness of fit; this is measuring the compatibility of each hydro-climatological data series with the theoretical probability distribution. It was done by using the Lilliefors (D), Anderson- Darling (AD) and Cramer -von Mises (CM) GoF tests at a significant level of $\alpha=0.05$. In all tests, the null hypothesis was $\mathrm{H}_{0}$; that the hydroclimatological data set comes from a population with a specified distribution, and the $\mathrm{H}_{1}$ when the dataset does not follow a specified distribution. Fourth, for each of the hydroclimatological data set the best-fit probability distribution model selected, the decision criteria used to report the outcome of statistical hypothesis in this study is the P-Value.
Thus accepting or rejection of a hypothesis was determined by comparing the P-value to the chosen level of significance $(\alpha)$. The P-value rule: Reject the null hypothesis when the Pvalue is less than or equal to, the level of significance $(\alpha)$, that is if $\mathrm{P}$-value $\leq \alpha$ reject $\mathrm{H}_{0}$, if $\mathrm{P}$-value $>\alpha$, then do not reject $\mathrm{H}_{0}$.

The theoretical probability distributions evaluated in this study are shown in table 2 for the hydro-climatological datasets. Choosing the best probability distributions was based on ranking of distributions that had the minimum sum of the test statistic, a method used by [28]. In this case the sum of the test statistic from the three GoFs was computed for each probability distribution model. Thenthe resulting sums of GoFs for each probability distribution model were sorted in ascending order from which the highest ranked distribution taken was one with the minimum sum of the test statistic.

Table 2. Description of Probability Distribution Functions used.

\begin{tabular}{|c|c|c|}
\hline Name of distribution & Probability Density Function & Parameters \\
\hline Normal & $f(x)=\frac{1}{\sqrt{2 \pi \sigma^{2}}} \exp \left[\frac{-1}{2}\left(\frac{x-\mu}{\sigma}\right)^{2}\right]$ & $\mu=$ Mean, $\sigma=$ Standard Deviation \\
\hline Exponential & $f(x)=\frac{1}{\lambda} e^{\frac{-1}{\lambda} x}$ & $\lambda>0$ \\
\hline Gamma & $f(x)=\frac{1}{\beta^{\alpha} \Gamma(\alpha)} x^{\alpha-1} e^{\frac{x}{\beta}}$ & $\begin{array}{l}\alpha=\text { shape parameter }(\alpha>0) \beta=\text { scale parameter }(\beta>0) \\
\Gamma=\text { Gamma function }\end{array}$ \\
\hline Weibull & $f(x)=\frac{\alpha}{\beta}\left(\frac{x}{\beta}\right)^{\alpha-1} \exp \left[-\left(\frac{x}{\beta}\right)^{\alpha}\right]$ & $\alpha=$ shape parameter $(\alpha>0) \beta=$ scale parameter $(\beta>0)$ \\
\hline Logistic & $f(\mathrm{x})=\frac{e^{\frac{-x-\mu}{\sigma}}}{\sigma\left(1+e^{-\frac{x-\mu}{\sigma}}\right)^{2}}$ & $\begin{array}{l}-\infty<\mu<\infty=\text { the mean } \\
\mu>0 \text { is scale parameter, } \sigma>0\end{array}$ \\
\hline Gumbel (Extreme value) & $f(\mathrm{x})=\frac{1}{\beta}-e^{\frac{x-\mu}{\beta}} e^{-e^{\frac{x-\mu}{\beta}}}$ & $\begin{array}{l}\infty<x<\infty \mu=\text { location parameter, } \\
\text { And } \beta=\text { scale parameter }\end{array}$ \\
\hline Chi Square & $f(x)=\frac{x^{\left(\frac{v}{2}\right)-1}}{\Gamma\left(\frac{v}{2}\right) 2^{\left(\frac{v}{2}\right)}} e^{(-x) / 2}$ & $\begin{array}{l}v(x>0) \text { : degrees of freedom; } \\
\gamma: \text { noncentering parameter }\end{array}$ \\
\hline
\end{tabular}

In addition two model selection criteria were used to select the probability distribution model that best fits the datasets, these are Akaike Information Criteria (AIC) and Bayes Information Criteria (BIC), and thus the distribution with the least values was selected. Finally from the three best ranked probability distribution models, the corresponding probability distribution model parameters are used to generate surrogate data series $\{\mathrm{G}\}_{\mathrm{i}}=1,2,3, \ldots \ldots, \mathrm{N}$. The residuals $\{\mathrm{R}\}_{\mathrm{j}}=1,2,3$ computed from the specification below are assessed.

$$
\mathrm{R}_{\mathrm{j}}=\left|\sum_{j=1}^{n}\left(Y_{i}-G_{i}\right)\right|
$$

Finally a distribution with minimum $\{\mathrm{R}\}$ is considered to be the best-fit probability distribution model for the hydroclimatology series.

\section{Results and Discussion}

\subsection{Descriptive Analysis of the Hydro-climatological Data and Temporal Variability}

The hydro-climatological datasets used in this study were categorized into monthly averages, seasonal and annual maxima data series as presented in table 1. Statistical moments characterizing each of the datasets are presented in table 3. Soil moisture content time series has moderate variation with monthly time series having more variation than seasonal i.e. with 17.36 and 10.58 standard deviation compared to other time series. Soil moisture content in general has large kurtosis values in all scales with more in monthly Soil moisture content indicative of high probability of dryness in hot months based on the negative skewness. The negative skewness demonstrates that in general soil moisture content for temporal scales is substantially asymmetrical with a long tail to the left, suggesting temporal variability in the variable for the observed data in the period when forest cover loss was detected.

The statistical moments in rainfall time series demonstrate temporal variability. Monthly and annual maxima rainfall time series exhibit the highest and lowest standard deviation indicative of dependence of the temporal resolution. The monthly rainfall time series has the highest variation i.e. has the highest standard deviation, with the lowest mean value and highest positive skewness indicating that monthly time series is substantially asymmetrical with a long tail to the right. Whereas both monthly and seasonal maxima rainfall time series are positively skewed, the annual maxima is negatively skewed demonstrating that for the study period on annual basis rainfall trends showed a decreasing trend at varying scale. The largest kurtosis value in monthly rainfall 
time series demonstrates that there is high probability of extreme rainfall values in the monthly datasets compared to annual rainfall.

The temporal variability in evapotranspiration time series in the study area is not highly pronounced based on the first and second moments in table 3 . The time series exhibit variability in monthly dataset, though with minimum variation in seasonal and annual maxima. The positive skewness at all time scales of the series considered indicates that evapotranspiration time series is substantially asymmetry with a long tail to the right.

Furthermore, the annual evapotranspiration maxima exhibit high positive kurtosis suggesting that the series is leptokurtic. This also imply that evapotranspiration time series is dependent on the time scale of observation with the probability of extreme values being present in annual series but changes slightly with a decrease in time scales.

The statistical moments in near surface temperature time series shows a non variation in time series with slight changes in annual temperature levels. No substantial changes are observed basing on the first and second moments. The temperature series exhibit positive skewness at all the time scale of the series implying a substantial asymmetrical with a long tail to the right. The monthly near surface temperature exhibit high positive kurtosis suggesting that there is high probability of observing extreme temperature values in monthly data as well as seasonal and annual. The implication of this is that the probability of getting high temperatures was high throughout the period, may be due to carbon-dioxide release from forest cover decline.

Table 3. Summary statistics of Lwamunda Catchment hydro-climatological data.

\begin{tabular}{|c|c|c|c|c|c|}
\hline \multicolumn{6}{|c|}{ StatisticalParameters } \\
\hline Data set & $\operatorname{Min} / \operatorname{Max}$ & Mean & Std. Dev & Skewness & Kurtosis \\
\hline \multicolumn{6}{|c|}{ Soil Moisture Content } \\
\hline Annual & 161.8/187.9 & 177.4 & 6.17 & -0.77 & 3.27 \\
\hline Seasonal & $139 / 188$ & 168.94 & 10.58 & -0.68 & 3.12 \\
\hline Monthly & $64.13 / 187.9$ & 153.76 & 17.36 & -0.79 & 4.63 \\
\hline \multicolumn{6}{|l|}{ Rainfall } \\
\hline Annual & $152.8 / 258.5$ & 211.1 & 26.62 & -0.09 & 2.42 \\
\hline Seasonal & $110 / 259$ & 170.66 & 35.08 & 0.26 & 2.23 \\
\hline Monthly & $26.15 / 258.5$ & 108.07 & 54.66 & 0.63 & 2.53 \\
\hline \multicolumn{6}{|c|}{ Evapotranspiration } \\
\hline Annual & $98.75 / 144.4$ & 115.51 & 9.5 & 0.77 & 4.25 \\
\hline Seasonal & $94 / 131$ & 108.3 & 8.19 & 0.519 & 2.82 \\
\hline Monthly & $60.14 / 144.4$ & 95.17 & 13.35 & 0.12 & 2.98 \\
\hline \multicolumn{6}{|c|}{ Temperature } \\
\hline Annual & $296.69 / 298.93$ & 297.73 & 0.61 & 0.11 & 2.34 \\
\hline Seasonal & $295.3 / 298.9$ & 296.7 & 0.88 & 0.68 & 2.62 \\
\hline Monthly & $294.42 / 298.9$ & 296.10 & 0.88 & 0.70 & 306 \\
\hline
\end{tabular}

\subsection{Assessment of the Probability Distribution and Goodness of Fit}

The following five probability distributions namely, normal, log normal, gamma, Weibull and exponential distribution were used to select the best fit probability distribution for annual maxima, seasonal maxima and monthly average of the hydro-climatological dataset for the study area. The description of the probability distribution functions are presented in Table 2. The goodness-of-fit tests, namely, Kolmogorov-Smirnov test which is the same as Lilliefors, Anderson-Darling test and Cramer-von Mises test were used at $\alpha(0.05)$ level of significance for the selection of the best fit distribution. For each dataset since it was continuous seven probability distributions were fitted, namely; Normal, Chi square, Gamma, Logistic, Extreme value maximum (Gumbel), Exponential and Weibull. The best fitted distribution is selected based on the minimum error produced, which is evaluated by the tests mentioned above. Tables 4-14 list the summary of the distribution parameters and the statistic for the GoF tests along with the associated probability values.

\subsubsection{Probability Distribution and Goodness of Fit for Annual Maxima Soil Moisture Content}

For the annual maxima soil moisture contenttime series, the probability distributions that had a better capability to reproduce the empirical cumulative distributions based on the GoF tests and with minimum sum of test statistic were Weibull, logistic using the $\mathrm{AD}$ and CvM tests; normal using Lilliefors (D) see (table 4). On the other hand, for the annual maximum rain fall, the most probable distribution functions that could reproduce the annual rainfall cumulative distributions were different which include chi square, gamma, and logistic using $\mathrm{AD}$ and CvM tests (see table 5). The differing probability distribution functions are explained by the changes in drivers and underlying compounding factors for rainfall. With regard to annual maximum evapotranspiration, the probability distributions capable of reproducing an empirical cumulative distribution are; logistic, gamma, and Gumbel (Extreme value maximum) using $\mathrm{AD}$ and $\mathrm{CvM}$ tests; also normal using the Lilliefors (D) (see table 6).

Table 4. Probability distributions and goodness of fit results for annual maxima soil moisture content. (NaN: not a number).

\begin{tabular}{|c|c|c|c|c|c|c|}
\hline \multirow[t]{2}{*}{ Distribution } & \multicolumn{2}{|c|}{ Llliefors (D) } & \multicolumn{2}{|c|}{$\begin{array}{l}\text { Anderson- } \\
\text { Darling (AD) }\end{array}$} & \multicolumn{2}{|c|}{$\begin{array}{l}\text { Cramer-Von } \\
\text { Mises (CVM) }\end{array}$} \\
\hline & Stat. & P-value & stat. & P-value & stat. & P-value \\
\hline Normal & 0.117 & $>0.1$ & 0.59 & 0.109 & 0.09 & 0.146 \\
\hline Chi square & $\mathrm{NaN}$ & $\mathrm{NaN}$ & 5.13 & $<0.005$ & 0.94 & $<0.005$ \\
\hline Gamma & $\mathrm{NaN}$ & $\mathrm{NaN}$ & 0.65 & 0.25 & 0.97 & 0.25 \\
\hline Logistic & $\mathrm{NaN}$ & $\mathrm{NaN}$ & 0.49 & 0.25 & 0.06 & 0.25 \\
\hline Gumbel & $\mathrm{NaN}$ & $\mathrm{NaN}$ & 1.51 & $<0.01$ & 0.23 & $<0.01$ \\
\hline Exponential & $\mathrm{NaN}$ & $\mathrm{NaN}$ & 27.43 & 0.000 & 1.12 & 0.000 \\
\hline Weibull & $\mathrm{NaN}$ & $\mathrm{NaN}$ & 0.24 & $>0.25$ & 0.034 & $>0.25$ \\
\hline
\end{tabular}

Furthermore with regard to near surface temperature data set the probability distributions selected for being capable of reproducing annual near surface temperature empirical cumulative distributions include logistic, Gumbel (Extreme value maximum) using $\mathrm{AD}$ and CvM tests while the normal probability distribution is fitted using the Lilliefors (D). The gamma distribution is also capable of reproducing the empirical cumulative distribution for the near surface temperature in the area where increased forest cover loss is 
reported (see table 7).

Table 5. Probability distributions and goodness of fit results for annual maxima rainfall. (NaN: not a number).

\begin{tabular}{lllllll}
\hline \multirow{2}{*}{ Distribution } & \multicolumn{2}{l}{ Lliefors (D) } & \multicolumn{2}{l}{$\begin{array}{l}\text { Anderson- } \\
\text { Darling (AD) }\end{array}$} & \multicolumn{2}{c}{$\begin{array}{l}\text { Cramer-Von } \\
\text { Mises (CVM) }\end{array}$} \\
\cline { 2 - 7 } & Stat. & P-value & stat. & P-value & stat. & P-value \\
\hline Normal & 0.093 & $>0.1$ & 0.24 & 0.75 & 0.04 & 0.73 \\
Chi square NaN & $\mathrm{NaN}$ & 1.15 & 0.25 & 0.12 & 0.25 & \\
Gamma & $\mathrm{NaN}$ & $\mathrm{NaN}$ & 0.25 & $>0.25$ & 0.03 & $>0.25$. \\
Logistic & $\mathrm{NaN}$ & $\mathrm{NaN}$ & 0.27 & $>0.25$ & 0.04 & $>0.25$ \\
Gumbel & $\mathrm{NaN}$ & $\mathrm{NaN}$ & 0.48 & 0.25 & 0.06 & 0.25 \\
Exponential & $\mathrm{NaN}$ & $\mathrm{NaN}$ & 26.14 & 0.000 & 0.81 & 0.000 \\
Weibull & $\mathrm{NaN}$ & $\mathrm{NaN}$ & 0.38 & $>0.25$ & 0.06 & $>0.25$ \\
\hline
\end{tabular}

\subsubsection{Probability Distribution and Goodness of Fit for Monthly AverageHydro-climatological Data}

The monthly average (extreme value) hydroclimatological data for soil moisture content, rainfall, evapotranspiration and temperature with the fitted probability distributions functions are summarized in tables 8-10. Goodness of fit tests is used to rank each distribution according to the minimum sum of test statistic. Tables $8-10$ provide a summary of the test statistic, table 8 illustrates that the monthly average soil moisture content time series is best fitted by normal distribution based on Lilliefors (D) and the Weibull distribution base on $\mathrm{AD}$ and CVM tests. In addition to the above since the study used monthly average time series the rainfall monthly average could not be fitted with any probability distributions.

Table 6. Probability distributions and goodness of fit results for annual maxima evapotranspiration. (NaN: not a number).

\begin{tabular}{lllllll}
\hline \multirow{2}{*}{ Distribution } & \multicolumn{2}{l}{ Llliefors (D) } & \multicolumn{2}{l}{$\begin{array}{l}\text { Anderson-Darling } \\
\text { (AD) }\end{array}$} & \multicolumn{2}{l}{$\begin{array}{l}\text { Cramer-Von } \\
\text { Mises (CVM) }\end{array}$} \\
\cline { 2 - 7 } & Stat. & P-value & stat. & P-value & stat. & P-value \\
\hline Normal & $\mathbf{0 . 1 3}$ & $>\mathbf{0 . 1}$ & $\mathbf{0 . 4 8}$ & $\mathbf{0 . 2 1}$ & $\mathbf{0 . 0 8}$ & $\mathbf{0 . 1 7}$ \\
Chi square & $\mathrm{NaN}$ & $\mathrm{NaN}$ & 1.95 & $<0.005$ & 0.33 & $<0.005$ \\
Gamma & $\mathrm{NaN}$ & $\mathrm{NaN}$ & 0.40 & $>0.25$ & 0.07 & $>0.25$ \\
Logistic & $\mathrm{NaN}$ & $\mathrm{NaN}$ & 0.33 & $>0.25$ & 0.05 & $>0.25$ \\
Gumbel & $\mathrm{NaN}$ & $\mathrm{NaN}$ & 0.46 & $>0.25$ & 0.09 & 0.25 \\
Exponential & $\mathrm{NaN}$ & $\mathrm{NaN}$ & 25.05 & 0.00 & 0.60 & 0.04 \\
Weibull & $\mathrm{NaN}$ & $\mathrm{NaN}$ & 1.23 & $<0.01$ & 0.19 & $<0.01$ \\
\hline
\end{tabular}

Table 7. Probability distributions and goodness of fit results for annual maxima near surface temperature. (NaN: not anumber).

\begin{tabular}{lllllll}
\hline \multirow{2}{*}{ Distribution } & \multicolumn{2}{l}{ Llliefors (D) } & \multicolumn{2}{l}{$\begin{array}{l}\text { Anderson- } \\
\text { Darling (AD) }\end{array}$} & \multicolumn{2}{l}{$\begin{array}{l}\text { Cramer-Von } \\
\text { Mises (CVM) }\end{array}$} \\
\cline { 2 - 7 } & Stat. & P-value & stat. & P-value & stat. & P-value \\
\hline Normal & 0.10 & $>0.1$ & 0.33 & 0.502 & 0.049 & 0.507 \\
Chi square & $\mathrm{NaN}$ & $\mathrm{NaN}$ & 11.29 & $<0.005$ & 2.40 & $<0.005$ \\
Gamma & $\mathrm{NaN}$ & $\mathrm{NaN}$ & 13.08 & $<1$ & 2.85 & $<1$ \\
Logistic & $\mathrm{NaN}$ & $\mathrm{NaN}$ & 0.35 & $>0.25$ & 0.05 & $>0.25$ \\
Gumbel & $\mathrm{NaN}$ & $\mathrm{NaN}$ & 0.55 & 0.25 & 0.06 & $>0.25$ \\
Exponential & $\mathrm{NaN}$ & $\mathrm{NaN}$ & 24.65 & 0.000 & 0.50 & 0.000 \\
Weibull & $\mathrm{NaN}$ & $\mathrm{Nan}$ & 0.65 & 0.05 & 0.11 & 0.05 \\
\hline
\end{tabular}

For monthly average evapotranspiration time series in table 9 depict that logistic, Gamma and Chi-square are the best to reproduce a better empirical cumulative distributions according to $\mathrm{AD}$ and $\mathrm{CVMGoF}$ tests. Table 10 provide summary of the temperature time series data that is best fit by Gumbel (Extreme value- maximum) and Gamma according to $\mathrm{AD}$ and $\mathrm{CVM}$ goodness of fit tests.

Table 8. Probability distributions and goodness of fit results for Monthly average soil moisture content. (NaN: not a number).

\begin{tabular}{lllllll}
\hline \multirow{2}{*}{ Distribution } & \multicolumn{2}{c}{ Lliefors (D) } & \multicolumn{2}{c}{$\begin{array}{l}\text { Anderson- } \\
\text { Darling (AD) }\end{array}$} & \multicolumn{2}{c}{$\begin{array}{l}\text { Cramer-Von } \\
\text { Mises (CVM) }\end{array}$} \\
\cline { 2 - 7 } & Stat. & P-value & stat. & P-value & stat. & P-value \\
\hline Normal & 0.043 & 0.083 & 1.64 & 0.003 & 0.198 & 0.0057 \\
Chi square & $\mathrm{NaN}$ & $\mathrm{NaN}$ & 2.87 & $<0.005$ & 0.38 & 0.005 \\
Gamma & $\mathrm{NaN}$ & $\mathrm{NaN}$ & 3.07 & $<0.005$ & 0.39 & $<0.005$ \\
Logistic & $\mathrm{NaN}$ & $\mathrm{NaN}$ & 1.47 & $<0.005$ & 0.17 & $<0.005$ \\
Gumbel & $\mathrm{NaN}$ & $\mathrm{NaN}$ & 15.94 & $<0.01$ & 2.34 & $<0.01$ \\
Exponential & $\mathrm{NaN}$ & $\mathrm{NaN}$ & 114.2 & 0.000 & 23.8 & 0.000 \\
Weibull & $\mathrm{NaN}$ & $\mathrm{NaN}$ & 0.65 & 0.1 & 0.105 & 0.1 \\
\hline
\end{tabular}

Table 9. Distributions and goodness of fit results for monthly average Evapotranspiration. (NaN: not a number).

\begin{tabular}{lllllll}
\hline \multirow{2}{*}{ Distribution } & \multicolumn{2}{l}{ Llliefors (D) } & \multicolumn{2}{c}{$\begin{array}{l}\text { Anderson- } \\
\text { Darling (AD) }\end{array}$} & \multicolumn{2}{c}{$\begin{array}{l}\text { Cramer-Von } \\
\text { Mises (CVM) }\end{array}$} \\
\cline { 2 - 7 } & Stat. & P-value & stat. & P-value & stat. & P-value \\
\hline Normal & 0.03 & $>0.1$ & 0.25 & 0.75 & 0.03 & 0.84 \\
Chi square & $\mathrm{NaN}$ & $\mathrm{NaN}$ & 0.61 & $>0.25$ & 0.09 & $>0.25$ \\
Gamma & $\mathrm{NaN}$ & $\mathrm{NaN}$ & 0.59 & 0.25 & 0.08 & 0.25 \\
Logistic & $\mathrm{NaN}$ & $\mathrm{NaN}$ & 0.49 & 0.25 & 0.05 & $>0.25$ \\
Gumbel & $\mathrm{NaN}$ & $\mathrm{NaN}$ & 4.05 & $<0.01$ & 0.64 & $<0.01$ \\
Exponential & $\mathrm{NaN}$ & $\mathrm{NaN}$ & 65.4 & 0.000 & 12.7 & 0.000 \\
Weibull & $\mathrm{NaN}$ & $\mathrm{NaN}$ & 1.85 & $<0.01$ & 0.25 & $<0.01$ \\
\hline
\end{tabular}

In general the probability distributions for monthly average time series have been fitted by different probability distributions models.

Table 10. Distributions and goodness of fit results for monthly average near surface temperature. (NaN: not a numer).

\begin{tabular}{lllllll}
\hline \multirow{2}{*}{ Distribution } & \multicolumn{2}{c}{ Llliefors (D) } & \multicolumn{2}{c}{$\begin{array}{l}\text { Anderson- } \\
\text { Darling (AD) }\end{array}$} & \multicolumn{2}{c}{$\begin{array}{l}\text { Cramer-Von } \\
\text { Mises (CVM) }\end{array}$} \\
\cline { 2 - 7 } & Stat. & P-value & stat. & P-value & stat. & P-value \\
\hline Normal & 0.09 & 0.000 & 4.13 & 0.000 & 0.68 & 0.000 \\
Chi square & $\mathrm{NaN}$ & $\mathrm{NaN}$ & 132.04 & $<0.005$ & 28.08 & 0.005 \\
Gamma & $\mathrm{NaN}$ & $\mathrm{NaN}$ & 151.04 & $<1$ & 32.8 & $<1$ \\
Logistic & $\mathrm{NaN}$ & $\mathrm{NaN}$ & 3.45 & $<0.005$ & 0.42 & $<0.005$ \\
Gumbel & $\mathrm{NaN}$ & $\mathrm{NaN}$ & 0.53 & 0.25 & 0.09 & 0.25 \\
Exponential & $\mathrm{NaN}$ & $\mathrm{NaN}$ & 39.29 & 0.000 & 7.06 & 0.000 \\
Weibull & $\mathrm{NaN}$ & $\mathrm{NaN}$ & 13.15 & $<0.01$ & 2.11 & $<0.01$ \\
\hline
\end{tabular}

\subsection{Probability Distributions and Goodness of Fit Seasonal Hydroclimatological Data}

The seasonal maximum soil moisture content, rain fall, evapotranspiration and near surface temperature time series were fitted with different probability distribution functions based on goodness of fit tests and the minimum sum of the test statistic to select the best fit model to the data. Tables 1114 provide a summary of the test statistic and selected best fit probability distributions. Table 11 illustrates that the seasonal time series of soil moisture content best fit by the Weibull 
and considered to be a best fit model to the seasonal maximum soil moisture content based on $\mathrm{AD}$ and $\mathrm{CVM}$ GoF tests. Thus it's capable of reproducing a better empirical cumulative distribution.

For the seasonal rain fall time series normal distribution is considered to be the best fit model based on Lilliefors (D), $\mathrm{AD}$ and CVM GoF tests. In addition the Gamma and Logistic distributions are also fitted to the time series data of seasonal rain fall thus capable of producing the empirical cumulative distribution intrinsic in the seasonal data see (table 12).

As for seasonal evapotranspiration Gamma and Gumbel (Extreme value -maximum) are distribution models that best fit the time series based on AD and CVM GoF tests.

Table 11. Distributions and goodness of fit results for Seasonal maxima soil moisture content. (NaN: not a number).

\begin{tabular}{lllllll}
\hline \multirow{2}{*}{ Distribution } & \multicolumn{2}{l}{ Llliefors (D) } & \multicolumn{2}{c}{$\begin{array}{l}\text { Anderson- } \\
\text { Darling (AD) }\end{array}$} & \multicolumn{2}{l}{$\begin{array}{l}\text { Cramer-Von } \\
\text { Mises (CVM) }\end{array}$} \\
\cline { 2 - 7 } & Stat. & P-value & stat. & P-value & stat. & P-value \\
\hline Normal & 0.112 & 0.003 & 1.025 & 0.01 & 0.15 & 0.017 \\
Chi square & $\mathrm{NaN}$ & $\mathrm{NaN}$ & 6.33 & $<0.005$ & 1.07 & $<0.005$ \\
Gamma & $\mathrm{NaN}$ & $\mathrm{NaN}$ & 1.27 & $<0.005$ & 0.19 & $<0.005$ \\
Logistic & $\mathrm{NaN}$ & $\mathrm{NaN}$ & 0.76 & 0.05 & 0.08 & 0.05 \\
Gumbel & $\mathrm{NaN}$ & $\mathrm{NaN}$ & 3.96 & $<0.01$ & 0.59 & $<0.01$ \\
Exponential & $\mathrm{NaN}$ & $\mathrm{NaN}$ & 25.56 & 0.00 & 3.84 & 0.000 \\
Weibull & $\mathrm{NaN}$ & $\mathrm{NaN}$ & 0.23 & $>0.25$ & 0.04 & $>0.25$ \\
\hline
\end{tabular}

Table 12. Distributions and goodness of fit results for seasonal maxima rain fall. (NaN: not a number).

\begin{tabular}{lllllll}
\hline \multirow{2}{*}{ Distribution } & \multicolumn{2}{l}{ Llliefors (D) } & \multicolumn{2}{c}{$\begin{array}{l}\text { Anderson- } \\
\text { Darling (AD) }\end{array}$} & \multicolumn{2}{c}{$\begin{array}{l}\text { Cramer-Von } \\
\text { Mises (CVM) }\end{array}$} \\
\cline { 2 - 7 } & Stat. & P-value & stat. & P-value & stat. & P-value \\
\hline Norma & 10.07 & $>0.1$ & 0.76 & 0.45 & 0.11 & 0.07 \\
Chi square & $\mathrm{NaN}$ & $\mathrm{NaN}$ & 25.5 & $<0.005$ & 1.92 & $<0.005$ \\
Gamma & $\mathrm{NaN}$ & $\mathrm{NaN}$ & 0.68 & 0.25 & 0.10 & 0.25 \\
Logistic & $\mathrm{NaN}$ & $\mathrm{NaN}$ & 0.94 & 0.005 & 0.10 & 0.25 \\
Gumbel & $\mathrm{NaN}$ & $\mathrm{NaN}$ & 0.85 & 0.05 & 0.13 & 0.05 \\
Exponential & $\mathrm{NaN}$ & $\mathrm{NaN}$ & 13.13 & 0.000 & 1.22 & 0.000 \\
Weibull & $\mathrm{NaN}$ & $\mathrm{NaN}$ & 0.88 & 0.025 & 0.12 & 0.025 \\
\hline
\end{tabular}

For the seasonal near surface temperature time series data the best fit model are the Gamma and Gumbel (Extreme value -maximum) probability distributions that better explains the data and thus capable of reproducing the empirical cumulative distribution intrinsic in the seasonal data of Lwamunda forest catchment.

Table 13. Distributions and goodness of fit results for Seasonal maxima evapotranspiration. (NaN: not a number).

\begin{tabular}{lllllll}
\hline \multirow{2}{*}{ Distribution } & \multicolumn{2}{l}{ Llliefors (D) } & \multicolumn{2}{l}{$\begin{array}{l}\text { Anderson- } \\
\text { Darling (AD) }\end{array}$} & \multicolumn{2}{l}{$\begin{array}{l}\text { Cramer-Von } \\
\text { Mises (CVM) }\end{array}$} \\
\cline { 2 - 7 } & Stat. & P-value & stat. & P-value & stat. & P-value \\
\hline Normal & 0.09 & 0.02 & 0.76 & 0.04 & 0.13 & 0.05 \\
Chi square & $\mathrm{NaN}$ & $\mathrm{NaN}$ & 6.69 & $<0.005$ & 1.02 & $<0.005$ \\
Gamma & $\mathrm{NaN}$ & $\mathrm{NaN}$ & 0.59 & 0.25 & 0.09 & 0.25 \\
Logistic & $\mathrm{NaN}$ & $\mathrm{NaN}$ & 0.74 & 0.05 & 0.09 & 0.05 \\
Gumbel & $\mathrm{NaN}$ & $\mathrm{NaN}$ & 0.33 & $>0.25$ & 0.05 & $>0.25$ \\
Exponential & $\mathrm{NaN}$ & $\mathrm{NaN}$ & 34.07 & 0.00 & 1.44 & 0.00 \\
Weibull & $\mathrm{NaN}$ & $\mathrm{NaN}$ & 2.203 & $<0.01$ & 0.33 & $<0.01$ \\
\hline
\end{tabular}

Table 14. Distributions and goodness of fit results for seasonal near surface temperature. (NaN: not a number).

\begin{tabular}{|c|c|c|c|c|c|c|}
\hline \multirow[t]{2}{*}{ Distribution } & \multicolumn{2}{|c|}{ Llliefors (D) } & \multicolumn{2}{|c|}{$\begin{array}{l}\text { Anderson- } \\
\text { Darling (AD) }\end{array}$} & \multicolumn{2}{|c|}{$\begin{array}{l}\text { Cramer-Von } \\
\text { Mises (CVM) }\end{array}$} \\
\hline & Stat. & P-value & Stat. & P-value & stat. & P-value \\
\hline Normal & 0.15 & 0.000 & 1.44 & 0.00 & 0.26 & 0.00 \\
\hline Chi square & $\mathrm{NaN}$ & $\mathrm{NaN}$ & 22.7 & $<0.005$ & 4.84 & $<0.005$ \\
\hline Gamma & $\mathrm{NaN}$ & $\mathrm{NaN}$ & 26.3 & $<1$ & 5.73 & $<1$ \\
\hline Logistic & $\mathrm{NaN}$ & $\mathrm{NaN}$ & 1.28 & $<0.005$ & 0.18 & $<0.005$ \\
\hline Gumbel & $\mathrm{NaN}$ & $\mathrm{NaN}$ & 0.44 & $>0.25$ & 0.69 & $>0.25$ \\
\hline Exponential & $\mathrm{NaN}$ & $\mathrm{NaN}$ & 46.57 & 0.00 & 0.706 & 0.00 \\
\hline Weibull & $\mathrm{NaN}$ & $\mathrm{NaN}$ & 2.80 & $<0.01$ & 0.506 & $<0.01$ \\
\hline
\end{tabular}

\subsection{Appropriate Probability Distribution for Each time Series Hydroclimatological Data Set}

In section 5.2 a set of probability distributions from the group of probability distributions that are capable of reproducing the properties of hydro-climatological data for the study area were selected for Lwamunda catchment area. In this section the study assesses the most appropriate probability distribution that fits each hydroclimatological dataset and capable of reproducing statistical moments for each of the data set. The selected family of probability distribution models derived from empirical distribution tests were further assessed through comparison of the generated statistical moments derived from the randomly generated empirical data and the actual observations. In addition the family of fitted distributions was checked on the criteria of maximizing $\log$ likelihood, and on both Akaike and Bayesian information criteria to determine which model was maximizing the likelihood and minimizing information criteria.

Thus for soil moisture content maxima time series, for annual maxima and seasonal maxima Weibull is considered to be the most capable of reproducing inherent statistics, while Normal distribution is the best for monthly averages. For rainfall annual and seasonal maxima series Chi square and Gamma are appropriate distributions respectively. Furthermore, for evapotranspiration annual and seasonal maxima; Logistic and Extreme value (Gumbel) are the most appropriate distributions capable of reproducing the statistical moments respectively while Normal is for monthly average evapotransipiration series. Finally for near surface temperature series, annual and seasonal maxima, the appropriate probability distributions are; Logistic and Gumbel respectively. Gumbel is the appropriate distribution capable of reproducing the statistical moments for both seasonal and monthly series.

\subsection{Discussion of Results}

The practice of fitting probability distribution models to data especially hydroclimatological data has been reported in literature $[29,30,31,32,36]$. In such studies, different probability distribution models were fitted to data series at watershed, catchment or point observations [33, 34]. The use of probability distribution models capable of reproducing the statistics of hydro-climatology data series is helpful in analyzing complex phenomena with compounding factors such as the interaction between land use change and water 
resources. Seven probability distributions have been analyzed to characterize hydro-climatology of Lwamunda forest catchment. These include; Weibull distribution, Normal distribution, Chi square, Gamma, Logistic and Extreme value maximum distribution (Gumbel). Three goodness of fit tests were applied: Lilliefor (D), Anderson Darling (AD) and Cramer van Mises, to evaluate the best fit probability distribution model. For each hydro-climatology dataset, the best fit model was selected on the basis of ranking metric. Soil moisture content was fitted by Weibull distribution for temporal scale series. Since the distribution is generally used for minimum values, it implied that for the period of 31 years (1980-2010) soil moisture content was of minimum values thus low water content in the soil. Hence there is a high probability that increases in land use change that preceded forest cover loss explains the reduction in water content for both crops and human consumption.

Rainfall series was fitted by Chi square and Gamma probability distribution for seasonal maximum. Since the Chi square is a special case of Gamma distribution, it implies that rainfall pattern in the study area is explained by Gamma family of distribution. This result confirms the findings of [35, 28]. Therefore rainfall events are due to some physical factors such as vegetation change. So extreme change in vegetation cover especially forest cover loss determines rainfall patterns. Furthermore, loss of water from soil and vegetation is explained by evapotranspiration and the best fit probability distribution for this hydro-climatology series are Logistic and Extreme value Maximum. The Logistic distribution is mostly used for growth modeling while Extreme value maximum distribution is used to model strength and life of an event. The implication of this is that with extreme bare soil (loss of vegetation) evapotransipration has a high probability of increasing in areas with more vegetation change. Similar results are reported by [22]. Regarding near surface temperature data series it is fitted by Logistic distribution and Extreme value maximum distribution signaling a high probability of increase in temperatures as more vegetation and forest cover is lost. The result is in agreement with expected increase in temperature due to vegetation loss [11, 18], this corroborates to studies in literature that forecast increase in temperature as more vegetation is lost.

\section{Conclusions}

The direction of forest cover change in the study area provides strong argument to assess the impact of land use change on water resources. Although the interactions between forest cover loss and water resources is complex, one way to understand it is to assess the impact using a probability distribution model which mimics the statistical moments of the underlying process from which conclusions are made. For hydro-climatology, fitting probability distributions to data is still open for many parts of SubSaharan Africa. In this current study a hydro-climatology data series comprised of monthly averages, seasonal and annual maximum series from Lwamunda forest catchment area have beenanalysed in order to determine appropriate probability distribution models of the underlying hydroclimatology. In the analysis seven probability distributions were considered. The GoF tests used were Lilliefors (D), Anderson Darling (AD), Cramer van Mises (CvM) to evaluate the best fit probability distribution model for each hydro-climatology data series. Since each data series had different probability distributions that fitted data, a ranking metric that used the test statistic from the three GoF tests was used to select the most appropriate probability distribution model capable of reproducing the statistics of the data series. The ranking metric considered the sum of the three GoF statistics and selected the one with minimum sum. On the basis of this selection criterion, results show that different best fit probability distribution models were different for the different data series. With the exception of soil moisture content for annual and seasonal maximum that had the same best fit model. In addition, evapotranspiration seasonal maximum and near surface temperature seasonal maximum as well as monthly near surface temperatures have the same best fit model. In general results show different models for different data series depending on location and on temporal scales which corroborate with those reported in literature. The soil moisture content data series was best fit by the Weibull probability distribution, rainfall series was best fit by Chi square and Gamma probability distributions. The evapotranspiration data series was best fit by Logistic and Extreme value maximum (Gumbel) probability distributions. Finally for near surface temperature was best fit by Logistic and Gumbel probability distributions. The contribution of this study is the use of hydro-climatological data series including soil moisture content to analyse a pattern of water resources variables (evapotranspiration and rainfall). The findings of this study are important for agricultural planning and to forest managers in simulation of forest degradation impacts on water resources.

\section{Acknowledgements}

I would like to acknowledge the comments by anonymous reviewers and monetary contribution from Islamic University In Uganda, Mbale to facilitate the publication of this work.

\section{References}

[1] Guido, D. S. Saleem, J. and Kaufmann (2002)."'Investigating Soil Moisture Feedbacks on Precipitation with tests of Granger causality". Advances in water resources. Vol. 25, pp 1305-1312.

[2] Shi Zhong, Tao Yong, Jian Zhu and Futing Wu (2019).”A modeling study of the Influence of initial soil moisture on summer precipitation during the East Asian Summer Monsoon". Dynamics of atmospheres and Oceans. Issue 85, pp. $72-82$.

[3] Nicholson, S. E., (2000) "The nature of rainfall variability over Africa on time scale of decades to millennia. Global Planet". Change, 26, 137-158, doi: 10.1016/S0921-8181(00)00040-0. 
[4] Li, X.-Y., P.-J. Shi, Y.-L. Sun, J. Tang, and Z.-P. Yang, (2006) "Influence of various in-situ rainwater harvesting methods on soil moisture and growth of Tamarixramosissima in thesemiarid loess region of China". For. Ecol. Manage., 233, 143-148, doi: 10.1016/j.foreco.2006.06.013.

[5] Kamruzzaman, M., S. Beecham, and A. V. Metcalfe, (2013) "Climatic influences on rainfall andrunoff variability in the southeast region of the Murray-Darling basin". Int. J. Climatol., 33, 291-311, doi: 10.1002/joc.3422

[6] Mubiru, D. N, Komutunga, E. Agona A. Apok, A and Ngara, T. (2012). "Characterising agrometeorological climate risks and uncertainities: crop production in Uganda", South African Journal of Sciences, Vol. 108, No 3/4, pp 108-118.

[7] Lazaro, R., F. S. Rodrigo, L. Gutierrez, F. Domingo, and J. Puigdefafregas, (2001) Analysis of a 30-year rainfall record (1967-1997) in semi-arid SE Spain for implications on vegetation." J. Arid Environ., 48, 373-395, doi: 10.1006/jare.2000.0755.

[8] Jackson, I. J., (1977) "Climate, Water and Agriculture in the Tropics”. Longman, 248 pp.

[9] Kizza Michael, et al, (2009). "Temporal rainfall variability in the Lake Victoria Basin in East Africa during the twentieth Century"Springer- Verlag.

[10] Government of Uganda (GOU), (2015). "Economic Assessment of the Impacts of Climate Change in Uganda, Final Study Report". Ministry of water and Environment, Climate Change Department, Kampala.

[11] Nsubuga, F. W. N.. Olwoch, J. M. and Rautenbach, C. J. dew and Botai, O. J (2014b). "Analysis of midtwentieth century rainfall trends and variability over southwestern Uganda". Theoretical and Applied Climatology, Vol. 115, pp 53-57.

[12] National Environment ManagementAuthority (NEMA). (2008). "State of Environment Report for Uganda 2008" National Environment Management Authority, Kampala, p. 282.

[13] Conway D. (2005). "From headwater tributaries to international river: Observing and adapting to climate variability and change in the Nile basin". Global Environmental Change, Vol. 15 No. 2, pp. 99-114. IJCCSM 10,5768 .

[14] Asadullah, A. Mcintyre, N. and Kigobe, M. (2008). "Evaluation of five satellite products for estimation of rainfall over Uganda". Hydrological Sciences Journal, Vol. 53 No. 6, pp. 1137-1150.

[15] Nsubuga, F. W. N. (2018). "Climate change and variability: A review of what is known and Ought to be known for Uganda". International Journal of Climate Change Strategies and management. Vol. 10, No. 3. pp 752-771.

[16] Nsubuga, F. W. N., Botai O. J., Olwoch, J. M. and Rautenbach, C. J. dew. Bevis, Y and Adetunji, A. O. (2014c). "The nature of rainfall in the main drainage sub-basins of Uganda". Hydrological Sciences Journal, Vol. 59 No. 2, pp 278-299.

[17] FEWSNET (2012). "Famine Early Warning Systems Network. A Climate Trend Analysis of Uganda" available at: ttp://pubs.usgs.gov/fs/2012/3062/FS2012-3062.pdf (accessed 9 January 2017 at 22: 45 CET).
[18] Nyanja, Pm. And Batelaan, O. (2009)."Estimating the effects of climate change on groundwater recharge and base flow in the upper Ssezibwa catchment, Uganda". Hydrological Sciences Journal. Vol 54. No. 4. Pp 713-726.

[19] Jassogne, L. Laderach, P. and Van Asten, P. (2013) "The impact of climate change on coffee in Uganda. Lessons from a case study in the Rwenzori Mountains". Oxfam Research Reports, IITA. CIAT, Oxfam, ISBN 978-1-78077-262-2. (accessed 10 January 2017 at 10: 25 CET).

[20] Badjeck, M. C. Allison, E. H. Halls, A. S and Dulvy, N. K. (2010). "Impacts of climate variability and change on fisherybased livelihoods". Marine Policy, Vol. 34 No. 3, pp 375-383.

[21] Kilimani, N. (2013). "Water resources accounts for Uganda: Use and policy relevancy". ERSA working paper No. 365.

[22] Nsubuga, F. W. N.. Olwoch, J. M. and Rautenbach, C. J. dew. (2014a) "Variability properties of daily and monthly observed near- surface temperatures in Uganda: 1960-2008". International Journal of Climatology, Vol. 34, pp. 303-314.

[23] Mingliang L. Hanquin T, Guangsheng C, Wei R, Zhang C and Jiyuan L. (2008) "Effects of land-use and land cover change on evapotransipiration and water yield in China during 19002000". Journal of the American Water Resources Association. Vol. 44. No. 5.

[24] Marcos H. C, Michael T. C, Guyot J L. (2009). "Effects of Climate variability and Deforestation on Surface water regimes. Amazonia and Global change, Geophysical Monograph series 186.

[25] Gautam, M. (2006)."Managing drought in sub-Saharan Africa: policy perspectives". Invited paper prepared for a Panel session on drought: Economic consequences and policies for mitigation at the IAAF conference, Gold cast, Queensland, Australia, August 12-18, 2006

[26] Shiferaw, B. Tesfaye K. Kassie, M. Abate, T. Prasanna, B. M, and Menkir, A. (2014) "Managing Vulnerability to drought and enhancing livelihood resiliencein sub-Saharan Africa: Technological, Institutional and Policy options". Weather and Climate Extremes, 3, 67-79.

[27] Ssentongo A. A, Darkey. D, and J. Mutyaba. (2018). Detecting forest cover and ecosystem service change using integrated approach of remotely sensed derived indices inthe central districts of Uganda. South AfricanJournal of Geomatics, Vol. 7, No. 1, pp 46-63.

[28] Basalirwa, C. P. K (1995). "Delineation of Uganda into climatological rainfall zones using the method of principal component analysis", International Journal of Climatology, Vol. 15, No 10, pp. 1161-1177.

[29] Muchuru S Botai, C. M, Botai J. O. and Adeola, A. M.(2015) "The hydrometeorology of the Kariba Catchment Area Based on the Probability Distributions" Earth interactions. Vol. 19, paper No. 14.

[30] Wan, H., X. Zhang, and E. M. Barrow. (2005) "Stochastic modeling of daily Precipitation for Canada". Atmos. Ocean, 43, 23-32, doi: 3137/ao.430102.

[31] Li, J. C. Sun and F. F. Jin (2013) "NAO Implicated as a predictor of Northern Hemisphere Mean temperature multidecadal Variability" Geophys. Res. Let, 40, 05497-5502. doi: 10.1002/2013GL057877. 
[32] Li, Z., W. Z. Liu, X. C. Zhang, and F. L. Zheng, (2011) "Assessing the site specific impacts of climate change on hydrology, soil erosion and crop yields in the Loess Plateau of China". Climatic Change, 105, 223-242, doi: 10.1007/s10584-010-9875-9.

[33] Fathian, F., S. Morid, and E. Kahya, (2015) "Identification of trends in hydrological and climaticvariables in Urmia Lake basin, Iran". Theor. Appl. Climatol., 119, 443-464, doi: 10.1007/s00704-014-1120-4.

[34] Ricci, V., (2005) “Fitting distributions with R". Rep., 35 pp. [Available online at http://cran.r-project.org/doc/contrib/Riccidistributions-en.pdf.]

[35] RajibMaity. (2018) "Statistical Methods in Hydrology and Hydroclimatology" Springer Transactions in civil and Environmental Engineering, https://doi.org/10.1007/978-98110-8779-0-4

[36] Tariq, M. M and Abbas, A. I (2016). "Fitting probability Distributions of Annual Raifall in Sudan". Journal of Engineering and computer sciences, Vol. 17, No 2.

[37] Conway Declan, et al (2004)."Rainfall variability in East Africa: Implications for natural resources management and livelihoods". The royal society.

[38] Chen, H., S. Guo, X. Ch-yu, and V. P. Singh, (2007)“Historical temporal trends of hydro-limaticvariables and runoff response to climate variability and their relevance in waterresource management in the Hanjiang basin. J. Hydrol., 344, 171-184, doi: 10.1016/j.jhydrol.2007.06.034.

[39] Eric, A. Davidson et al. (2000). "Effects of soil water content on soil respiration in forests and cattle pastures of Eastern Amazonia". Kluwer Academic Publishers, Netherlands. Biogeochemistry 48: 53-69.

[40] Eke, C. Osuij G. Amaeze and Nwosu, D. Felix. (2005). "Modeling of Nigeria's Economic Growth Rate: A Probability Distribution Fitting Approach" Asian Journal of Probability and Statistics. Vol. 2, No. 1. Pp 1-17.

[41] Nsubuga, F. W. N.. Olwoch, J. M. and Rautenbach, C. J. dew. (2011).“Climate trends at Namulonge in Uganda". Journal of Geography and Geology, Vol. 3 No. 1, pp. 119-131.

[42] Sambe, N. L. Adeofun, O. C. and Dachung, G.(2018). "The Economic and Ecological Effects of Deforestation on the Nigerian Environment."Asian Journal of Advanced Research and Reports, 1 (2), 1-25. Retrieved from http://www.journalajarr.com/indexphp/AJARR/article/view/13 038 .

[43] Valli, M., S. S. Kotapati, and V. M. K. Iyyanki, (2013) Analysis of Precipitation Concentration Indexand Rainfall Prediction in various Agro-Climatic Zones of Andhra Pradesh, India. Int. Res. J. Environ. Sci., 2, 53-61. 